\title{
Service robots: value co-creation and co-destruction in elderly care networks
}

Citation for published version (APA):

Caic, M., Odekerken-Schroder, G., \& Mahr, D. (2018). Service robots: value co-creation and codestruction in elderly care networks. Journal of Service Management, 29(2), 178-205. https://doi.org/10.1108/JOSM-07-2017-0179

Document status and date:

Published: 01/01/2018

DOI:

10.1108/JOSM-07-2017-0179

Document Version:

Publisher's PDF, also known as Version of record

Document license:

Taverne

Please check the document version of this publication:

- A submitted manuscript is the version of the article upon submission and before peer-review. There can be important differences between the submitted version and the official published version of record.

People interested in the research are advised to contact the author for the final version of the publication, or visit the DOI to the publisher's website.

- The final author version and the galley proof are versions of the publication after peer review.

- The final published version features the final layout of the paper including the volume, issue and page numbers.

Link to publication

\footnotetext{
General rights rights.

- You may freely distribute the URL identifying the publication in the public portal. please follow below link for the End User Agreement:

www.umlib.nl/taverne-license

Take down policy

If you believe that this document breaches copyright please contact us at:

repository@maastrichtuniversity.nl

providing details and we will investigate your claim.
}

Copyright and moral rights for the publications made accessible in the public portal are retained by the authors and/or other copyright owners and it is a condition of accessing publications that users recognise and abide by the legal requirements associated with these

- Users may download and print one copy of any publication from the public portal for the purpose of private study or research.

- You may not further distribute the material or use it for any profit-making activity or commercial gain

If the publication is distributed under the terms of Article $25 \mathrm{fa}$ of the Dutch Copyright Act, indicated by the "Taverne" license above, 
JOSM

29,2

\section{8}

Received 28 July 2017 Revised 6 December 2017 5 February 2018 Accepted 6 February 2018

\section{Service robots: value co-creation and co-destruction in elderly care networks}

\author{
Martina Čaić and Gaby Odekerken-Schröder \\ Department of Marketing and Supply Chain Management, \\ School of Business and Economics, Maastricht University, \\ Maastricht, The Netherlands, and \\ Dominik Mahr \\ School of Business and Economics and Service Science Factory, \\ Maastricht University, Maastricht, The Netherlands
}

\begin{abstract}
Purpose - The purpose of this paper is to investigate the potential roles for service robots (i.e. socially assistive robots) in value networks of elderly care. Taking an elderly person's perspective, it defines robot roles according to their value co-creating/destroying potential for the elderly user (i.e. focal actor), while acknowledging consequences for a network of users around the elderly (i.e. network actors).

Design/methodology/approach - This qualitative, interpretative study employs in-depth phenomenographic interviews, supported by generative cards activities (i.e. Contextual Value Network Mapping), to elicit an elderly person's tacit knowledge and anticipate the effects of introducing an automated actor on institutionalized value co-creation practices.

Findings - The proposed typology identifies six roles of socially assistive robots in an elderly person's value network (enabler, intruder, ally, replacement, extended self, and deactivator) and links them to three healthsupporting functions by robots: safeguarding, social contact, and cognitive support.

Research limitations/implications - Elderly people have notable expectations about the inclusion of a socially assistive robot as a new actor in their value networks. The identified robot roles inform service scholars and managers about both the value co-destruction potential that needs to be avoided through careful designs and the value co-creation potential that should be leveraged.

Originality/value - Using network-conscious phenomenographic interviews before the introduction of a novel value proposition sheds new light on the shifting value co-creation interplay among value network actors (i.e. elderly people, formal and informal caregivers). The value co-creation/destruction potential of socially assistive robots and their corresponding roles in care-based value networks offer insights for the design of meaningful robotic technology and its introduction into the existing service networks.
\end{abstract}

Keywords Value co-creation/destruction, Value networks, Socially assistive robots, Elderly care services, Future service scenarios, Service design

Paper type Research paper

\section{Introduction}

The success of a new service depends on the value it creates for the user but also on the value it creates or destroys for the network in which that user is embedded. For example, smart alarm systems for consumers' homes might increase one family member's feelings of security, while other members find the false alarms and constant notifications stressful and feel more vulnerable when relying on such technology. In weighing the benefits and risks, each member of the network might support or impede an individual's acceptance of a service, particularly if it is co-created in a novel way. According to Skålén et al. (2015), a service innovation implies new value propositions that hold promises of value creation for a diverse set of actors. If service providers hope to encourage individuals to adopt an innovative, future service scenario, they must understand the value networks in which these individuals interacts and the impact that a new service will have on the value created/destroyed therein. Such a holistic perspective can offer service managers insights 
into the disruptive nature of a new service and its effect on value co-creation and co-destruction throughout the value network.

Healthcare offers an ideal setting in which to investigate value co-creation/destruction in networks, because it comprises complex webs of interactions among multiple actors, technology, and ambiguous institutional rules and norms (Black and Gallan, 2015; McColl-Kennedy et al., 2012, 2016). Many new services in healthcare, especially technology-intensive ones (e.g. healthcare robots, Telehealth), confront resistance (Broadbent et al., 2009; Green et al., 2016). In this setting, an especially critical segment to study is the growing elderly population, with its strong network characteristics and generally lower receptiveness to new technologies (Smith, 2015). This population is expected to increase by a staggering 18-28 percent by 2060 (European Commission (DG ECFIN) and the Economic Policy Committee (AWG), 2015), putting great stress on national systems and compelling innovative solutions to ensure the well-being of the elderly while also enabling formal (i.e. professional care staff) and informal (i.e. family and friends) actors to perform service functions. For example, the well-being of the elderly and their network of caregivers may be improved by socially assistive robots, which may enhance seniors' quality of life and alleviate their sense of solitude and isolation (Augusto et al., 2012). Socially assistive robots can understand social cues through facial and voice recognition technology, interact with users in human-like manners, and assist with health monitoring and household activities (KPMG, 2016; Robinson et al., 2014). However, elderly people and their value networks of formal and informal caregivers have exhibited some reluctance to accept robotic services (Broadbent et al., 2009; International Federation of Robotics, 2015); this reluctance is a key challenge for service innovators in this and other fields where technology enables value networks.

The existing robotics literature explores both desirable and undesirable effects of introducing socially assistive robots in elderly care (e.g. Ray et al., 2008; Robinson et al., 2014); yet it mainly addresses positive roles of the robot to the neglect of unwanted roles elderly people attach to the robot. In contrast, current service research does consider a service innovation as a positive or negative change in value for different network actors (Plé and Chumpitaz Cáceres, 2010; Skålén et al., 2015; Snyder et al., 2016). However, no empirical studies take both value co-creating and co-destroying potentials of a future robotic service into account. Especially for services which involve both human and non-human actors (Breidbach and Maglio, 2016; Lusch and Nambisan, 2015), researchers need to look for novel ways to evaluate expected value transformations for different individuals within value networks. This implies advancing existing research methods to better capture the network element.

To address these gaps, the current study provides three main contributions. First, it introduces socially assistive robots as actors in value networks and identifies their value propositions through acting in human-like manners. An underlying assumption is that "value is always uniquely and phenomenologically determined by the beneficiary" (Vargo and Lusch, 2016, p. 18). Accordingly, the central research question asks:

$R Q$. How do focal actors (e.g. elderly people) perceive the roles of socially assistive robots in their care-based value networks, in terms of the expected value co-creation/destruction potential with themselves and other network actors?

Specifically, this study demonstrates that human-like robots that are capable of engaging with users on a social level, through facial and voice recognition technology (i.e. high automated social presence; van Doorn et al., 2016), offer both value co-creating and co-destroying potential. This ambidexterity provides a more balanced view of socially assistive robots and advances research on the complementary or substitutive nature of technology in service networks. 
JOSM

29,2

Second, the study advances scholarly understanding of value creation practices by taking a network-conscious approach that covers both the value co-creating and co-destroying potential. Such an approach aligns with recent trends in service research, to shift the innovation foci from an individual actor toward relationships in value networks - for this study defined as "service beneficiaries' conceptualizations of actor constellations and their value co-creating/destroying dynamics for a particular service." The resulting typology extends existing role conceptualizations (e.g. McColl-Kennedy et al., 2012; Moeller et al., 2013), to encompass not only value co-creation and co-destruction counterparts, but also to address network-conscious elements. This study takes the focal actor's perspective, which acknowledges other pivotal actors and value creation constellations. The novel focus on future, rather than current, value co-creation and co-destruction can stimulate service innovation in complex service systems, such as healthcare (Danaher and Gallan, 2016).

Third, the network-conscious approach to technology-enabled services advances insights on how to design complex service systems (Chandler and Lusch, 2015). To address the need for more suitable methods to understand value co-creation/destruction in value constellations, this study introduces a "Context Disruption" interview method - a generative technique that uses vivid representations of future service scenarios to collect data-rich narratives. This phenomenographic approach (Sandberg, 2000) integrates in-depth exploratory interviews (i.e. Context Disruption interviews) with generative cards activities (i.e. Contextual Value Network Mapping) to elicit elderly informants' tacit knowledge and probe anticipated effects of a future service (co-created with an automated actor) on existing value co-creation practices, in relation to the elderly self and other network actors. This methodological contribution can help service researchers address a key service research priority, that is, designing adaptive service systems to respond to dynamic environments (Ostrom et al., 2015).

\section{Theoretical background}

Value co-creation/destruction in networks

Service systems can be defined as "configurations of people, technologies, and other resources that interact with other service systems to create mutual value" (Maglio et al., 2009, p. 395). Contemporary service systems are increasingly complex, not least due to disruptive, rapidly evolving information technologies (e.g. robotics, big data, social networking; Ostrom et al., 2015; Rust and Huang, 2014). To improve acceptance of technology-enabled service innovations, service providers need to translate their technical aspects into value for different individuals involved. In line with Skålén et al. (2015) who equate service innovation with "the creation of new value propositions" for involved actors (p. 137), it also entails shifting the focus from new features of an offering to formulating compelling value propositions and inviting network actors to collaboratively create value. The service literature views value as being created when engaging in the service leaves actors better off or increases their well-being relative to their initial conditions (Grönroos, 2008; Prahalad and Ramaswamy, 2004). Yet service interactions can also result in diminished or destroyed well-being for at least some actors in the value network (Echeverri and Skålén, 2011; Plé and Chumpitaz Cáceres, 2010).

Zooming in on a service system uncovers the multiple value networks that constitute it and whose actors can be affected by a novel service, including service delivery (Tax et al., 2013) and customer (Epp and Price, 2011; Schau et al., 2009) networks. Using Normann and Ramírez's (1993) notion of value networks as a mental construct and adopting the view that service beneficiaries ultimately assess which actors take part in value co-creation, this study defines value networks "as service beneficiaries' conceptualizations of actor constellations and their value co-creating/destroying dynamics for a particular service." Therefore, future 
services should be evaluated through the trade-off of value co-creation and value co-destruction potential for different actors in the value network. Although several authors explore value co-creation within networks of multiple actors (Cova and Salle, 2008; Pinho et al., 2014), empirical research on value co-creation in network contexts is largely lacking. Especially in the healthcare environment with changes due to digitization, automation, and human-to-non-human interactions (Breidbach and Maglio, 2016; Danaher and Gallan, 2016), it is necessary to rethink value. More in particular, how new technology-enabled service interactions among multiple actors result in strengthened or weakened well-being of the individuals involved.

Following the definition of value networks, the knowledge of network actors serves as an important asset for improved design of service systems. When designing service systems, researchers often utilize system (e.g. service blueprints, system maps; Patrício et al., 2011) and network (e.g. service delivery network; Tax et al., 2013) visualizations. While customer-centric, these mapping approaches are not without shortcomings. First, they often rely on the service provider's perspective, hence excluding service beneficiaries themselves from the mapping process. Second, they focus on the structure (i.e. number and configuration of actors; Briscoe et al., 2012) and flows of goods, information, or money, rather than value co-creation. Such research approaches cannot capture service beneficiaries' understanding of value co-creating networks or the importance of different actors for the realization of value.

\section{Socially assistive robots in elderly care}

The study context centers on service robots, in particular socially assistive robots in elderly care. Understanding their role in elderly care demands a close consideration of the origins of this technology. Robotic developments traditionally were motivated by aspirations to automate repetitive, tedious, complex, or time-consuming tasks (Matarić, 2017). In healthcare, the first generation of robots primarily assisted with the tasks that were difficult for either the patient or healthcare professionals (Broadbent et al., 2009). The value proposition for these assistive robots emphasized functional assistance to humans, through physical interaction (Feil-Seifer and Matarić, 2005), such as robotic exoskeletons that augmented humans' physical capacity in areas they suffered weaknesses (Perry et al., 2007). Accordingly, these early assistive robots took functional roles, like assistants, helpers, servants, and butlers (Dautenhahn et al., 2005; Fong et al., 2003). Parallel to their development, a new generation of robots appeared, with a primary value proposition of engaging in social interactions. These socially interactive robots (Fong et al., 2003) are autonomous and can interact with people in a human-like way (Breazeal, 2004). For example, the socially interactive robot Jibo looks, listens, learns, and reacts with expressive movements and responses (van Camp, 2017). Such robots perform affect-based roles, as conversation partners or socially interactive peers (Fong et al., 2003).

Along with technological developments, robots' social dexterity improved, creating new avenues for providing social support. Accordingly, the latest generation of robots combines assistive and socially interactive functions. These socially assistive robots offer assistance through social interactions in a human-like manner as their main value proposition (Feil-Seifer and Matarić, 2005). In a healthcare context, socially assistive robots are autonomous, understand social cues through facial and voice recognition, and can provide both child (e.g. autism therapy; Huijnen et al., 2016; Scassellati et al., 2012) and elderly (e.g. medication reminders, Broekens et al., 2009) care. As they perform more socially engaging tasks (e.g. health promotion, consoling), these robots take roles of companions, collaborators, partners, pets, or friends (Dautenhahn et al., 2005; Fong et al., 2003). Figure 1 summarizes these three types of robots.

\section{Value propositions of socially assistive robots}

In an elderly care context, the value proposition of socially assistive robots relates to their offer of both assistive and social value co-creation potential, through services such as 
JOSM

29,2

\section{2}

Figure 1.

Robot types

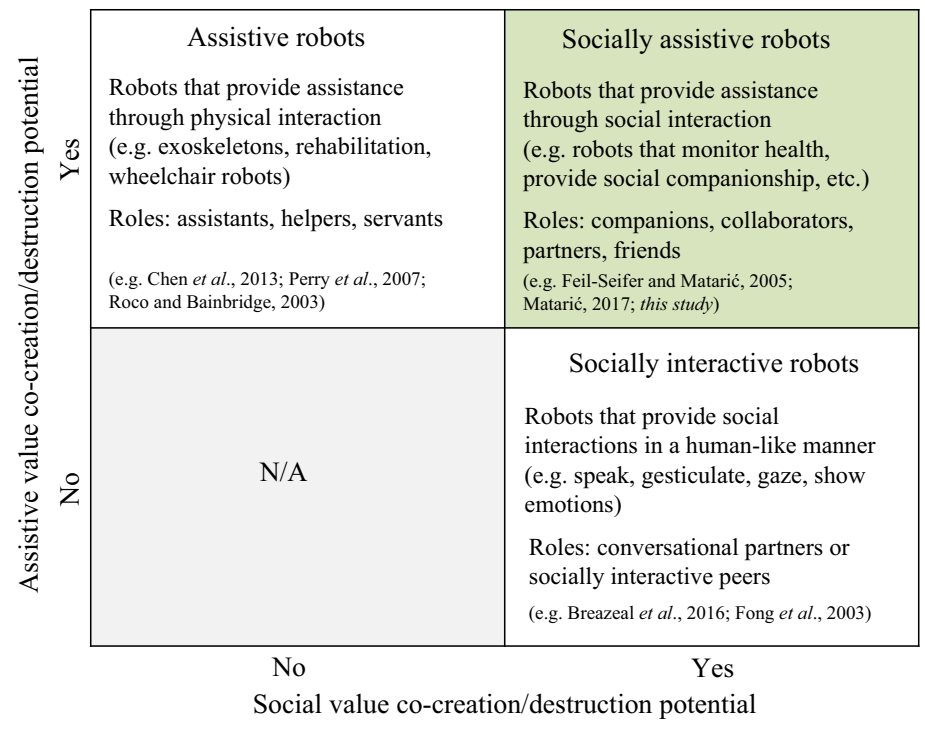

health monitoring and safety, encouragement to engage in rehabilitation or general health-promoting exercises, social mediation, interactions, and companionship (Feil-Seifer et al., 2007). Several studies note the variety of benefits of socially assistive robots in elderly care, including reduced stress and loneliness, prolonged independence, maintained dignity, and improved well-being and quality of life (Broekens et al., 2009; Feil-Seifer et al., 2007; Ray et al., 2008; Robinson et al., 2014). Yet as is true of many service innovations, introducing socially assistive robots in elderly care also can lead to undesirable consequences, such as a loss of privacy, stigma of disability, fear of even greater dependence, or reduced human contact (Broadbent et al., 2009; Ray et al., 2008). These potentially negative effects might hinder acceptance among or motivation by elderly users to interact with socially assistive robots. But interaction with the robot is the only way for people to perceive it as user-friendly or come to feel physically, emotionally, and cognitively comfortable in its presence (Broadbent et al., 2009).

An additional layer of complexity marks the introduction of socially assistive robots in elderly care settings, because this context also involves a network of formal and informal caregivers. Their opinions and cooperation can be crucial for the effective operation of an automated actor. Therefore, the robot also must be responsive to the needs and requirements of various network actors (Feil-Seifer and Matarić, 2005), a challenge that has been largely neglected in the existing research. In particular, the potential negative consequences of these service innovations, or value co-destruction, remain unexplored. To advance understanding of the role of socially assistive robots in elderly care, this study therefore considers both the value co-creation and the value destruction potential of robots, according to the perspective of the focal network actor (i.e. elderly person) in a network context.

\section{Methodology}

To capture the value of a novel service within the value network, emphasizing the beneficiary's experienced and expected value-in-use/context, a phenomenographic approach is appropriate (Sandberg, 2000). Such an approach is in line with the premise that value is always phenomenologically defined by the beneficiary (Vargo and Lusch, 2016). 
This methodology collects first-person descriptions of focal actors' context-dependent experiences (Schembri and Sandberg, 2002) and expectations of a service innovation. For this study, in-depth exploratory interviews were augmented with generative cards activities (Sanders, 2000), referred to as a Context Disruption interview protocol (see Appendix 2), designed to uncover what informants find valuable within their personal contexts. The choice of a qualitative interpretative approach reflects the research goal of building, rather than testing, theory (Lincoln and Guba, 1985).

Traditional qualitative techniques (e.g. interviews, focus groups) gather explicit knowledge (i.e. what informants verbally articulate), which limits understanding of contextual complexity (Sleeswijk Visser, 2009). Instead, for this study, the informants were actively engaged through generative elements (e.g. by asking them to visualize their network contexts). The semi-structured nature of the interview protocol helped capture rich descriptions of the focal actors' network experiences and evaluations of novel value propositions (i.e. narratives). Simultaneously, the generative card mechanisms (Sanders, 2000) elicited their tacit knowledge (Polanyi, 1967), through network visualizations. Thus, informants' tacit knowledge could be represented by tangible artifacts that, combined with data-rich narratives, represent elderly people's perceptions and expectations of robotic technology infusion into their value networks.

\section{Research protocol: Context Disruption}

After the initial recruitment of elderly persons, only those who expressed interest in participating in a broader study of the use of robots were invited to subsequent, individual interview sessions. In line with the request of the Ethical Review Committee, which approved the proposed research protocol, all informants signed an informed consent form before answering an initial set of demographic questions. After the collection of this general background information, informants entered a four-step, generative, Context Disruption interview protocol (see Table I and Appendix 2). Considering the novelty of this method, the next sections detail the reasoning behind and objectives for engaging informants in each step.

Step 1. Contextual Value Network Mapping, status quo. In the first step, informants had to think about their everyday life experiences and different people who take part in what was defined as their care-based value network (i.e. informal and formal connections who are more or less actively involved in taking care of them, helping them with groceries, medicine intake, finances, moral support). Furthermore, they engaged in Contextual Value Network Mapping using a set of specifically designed cards. The mapping activity consisted of three steps: selecting appropriate network actors from a deck of network actor cards, rearranging the selected cards into a conceptualized network configuration, and adding the relations (i.e. pathways of value co-creation) among the different actors.

The use of cards for the data collection elicits lively accounts of experiences and helps make the informants' networks tangible (Clatworthy, 2011). Both images and text were placed on the cards to ensure unambiguous understanding of their content (Figure 2). Thus this activity could collect both "what they say" (i.e. narratives built around the visualizations, in response to probing questions) and "what they make" (i.e. care-based value network visualizations;

\begin{tabular}{lll}
\hline Step Name & Description \\
\hline (1) Contextual Value Network & $\begin{array}{l}\text { Map the care-based value network before the introduction of the } \\
\text { socially assistive robot }\end{array}$ \\
Mapping, status quo & Sensitize respondents to a variety of new technology usages \\
(2) Active immersion & Introduce, assess, and prioritize socially assistive robot functions \\
(4) Contextual Value Network & Map the care-based value network after the introduction of the \\
& Mapping, future condition & socially assistive robot
\end{tabular}


JOSM

29,2

184

Figure 2.

Network actor cards
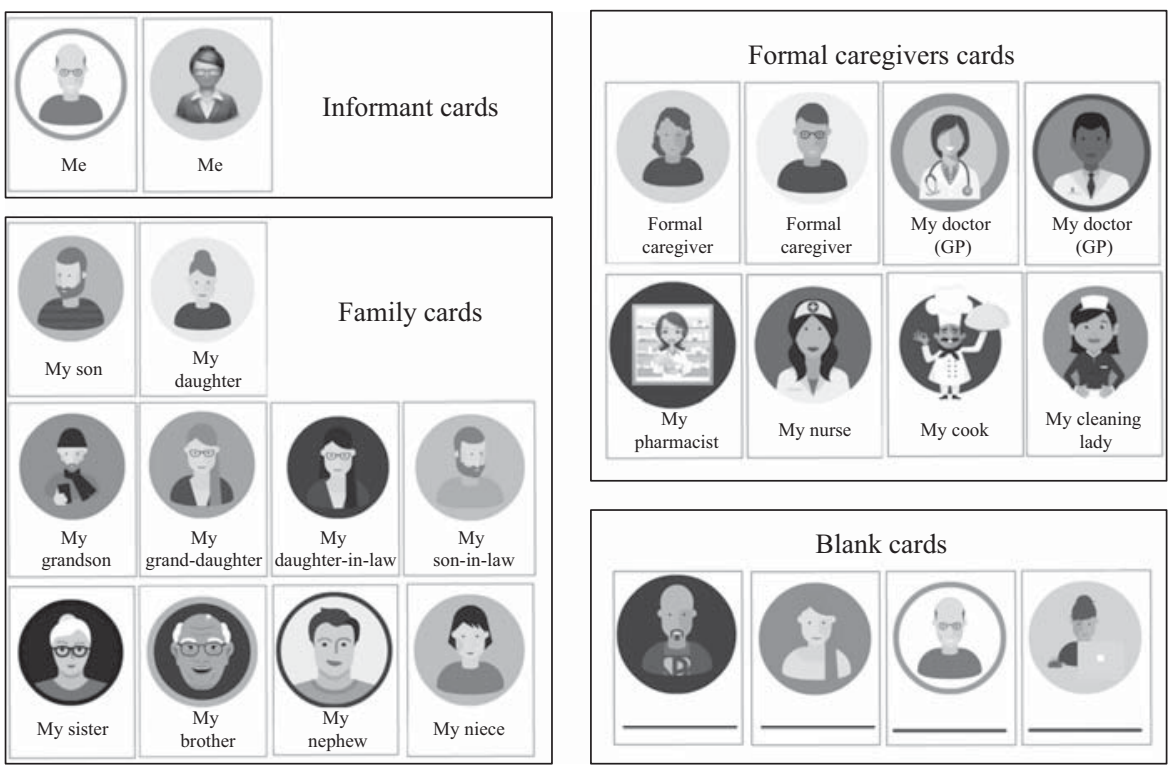

Note: Blank cards provided informants the opportunity to add new actors to the set

Sanders, 2000). The result was a comprehensive, holistic view of the key actors in their networks, their roles in value co-creation, the elderly people's evaluations of the novel value proposition (i.e. service innovation), and their perceptions of how other network actors evaluate it. Informants' experiences and evaluations were not presumed to be understood but rather were encouraged to be expressed through "what" and "how" questions (Sandberg, 2000). The collected insights from this first step detailed informants' existing care-based value networks, or the status quo, before the network relations and structures became disrupted by a socially assistive robot.

Step 2. Active immersion. In the second step, informants were sensitized (Sleeswijk Visser, 2009) to the topic of new technology usage and encouraged to share narratives about satisfying and dissatisfying encounters with a variety of technology. The objective of this step was to set the stage for the introduction of the socially assistive robots, which are unfamiliar technological tools that may affect informants' care-based value networks. The questions were designed to elicit the informants' new technology readiness and identify reasons for their acceptance or rejection of previous waves of technological advancements (e.g. PCs, smartphones, tablets).

Step 3. Introducing "disruption". In the third step, informants became acquainted with a socially assistive robot project; they were part of the pretrial phase of this broader project. The robot's look and feel was evoked through photographs and robot functions cards (Figure 3 and Appendix 2). Each of its 12 functions was explained using a simple description and vivid example. Informants were encouraged to share their opinions after each introduced function. Then they indicated the three functions they deemed most important/useful and least important/useful. This step thereby collected their genuine needs and enabled the interviewer to delve deeper into the desired value outcomes among the elderly informants.

Also in this step, informants indicated their overall impression of the robot and whether they would welcome such an innovation in their lives. To collect their different perceptions of robotic care and predictions about transformations in their network relations, 
(a)
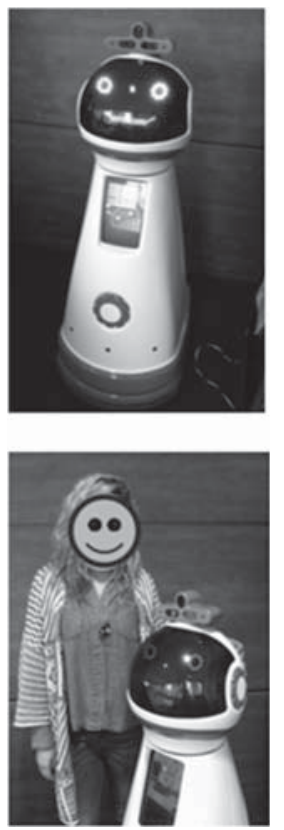

(b)
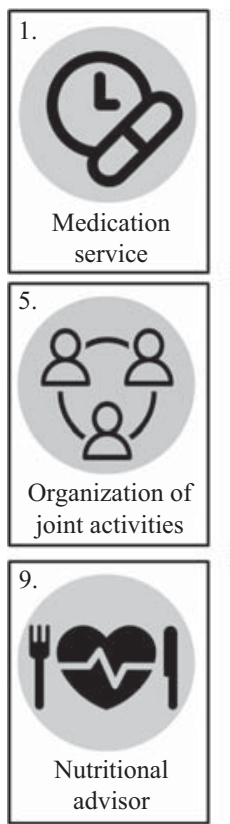
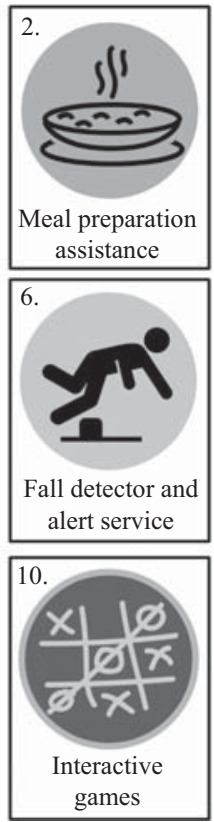
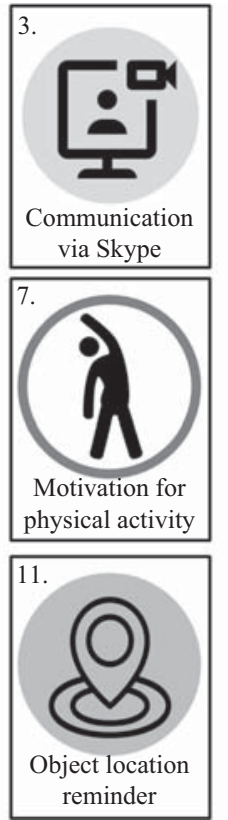
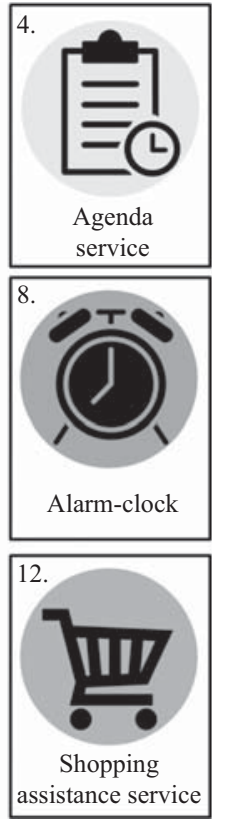

Notes: (a) Sample photographs; (b) robot functions cards

Service robots

185

Figure 3.

Tangible tools

the interviewer used probing questions to covertly elicit both the value-creating and value-destroying potential of the robot.

Step 4. Contextual Value Network Mapping, future condition. In the fourth and final step, informants again were invited to engage in Contextual Value Network Mapping, with an additional robot card added to the deck of network actors. They were encouraged to imagine a hypothetical situation in which the socially assistive robot becomes a part of their care-based value networks (i.e. starts residing in their homes and supports their daily activities). The objective was to determine whether and how their conceptualization and visualization of their care-based value networks would change, relative to the first step of the study (see Figure 4 and Appendix 2).

In particular, informants indicated who, from their respective networks, would be granted access to the information stored in the robot, whether there would be different layers of the information access, and if so, why. Furthermore, they indicated which network actors would be first alerted in case of an emergency. More focused probing questions revealed the position of the robot in the care-based value network, its proximity to the focal actor, and its underlying role.

\section{Sample}

The sample included 20 elderly persons, ten females and ten males, with only minimal age-related health conditions (see Table A1 in Appendix 1). Elderly persons suffering from severe physical (e.g. full physical immobility) or mental (e.g. dementia) health problems were excluded from consideration, as well those with no autonomy in their daily activities or who were incapable of giving consent. The target population comprised of elderly persons living alone at home (i.e. independent living), in a nursing home, or at home with the assistance of formal or informal caregivers. The interviews were conducted in person, in informants' 
JOSM

29,2

\section{6}

Figure 4.

Examples of value network visualizations from the elderly persons' perspectives

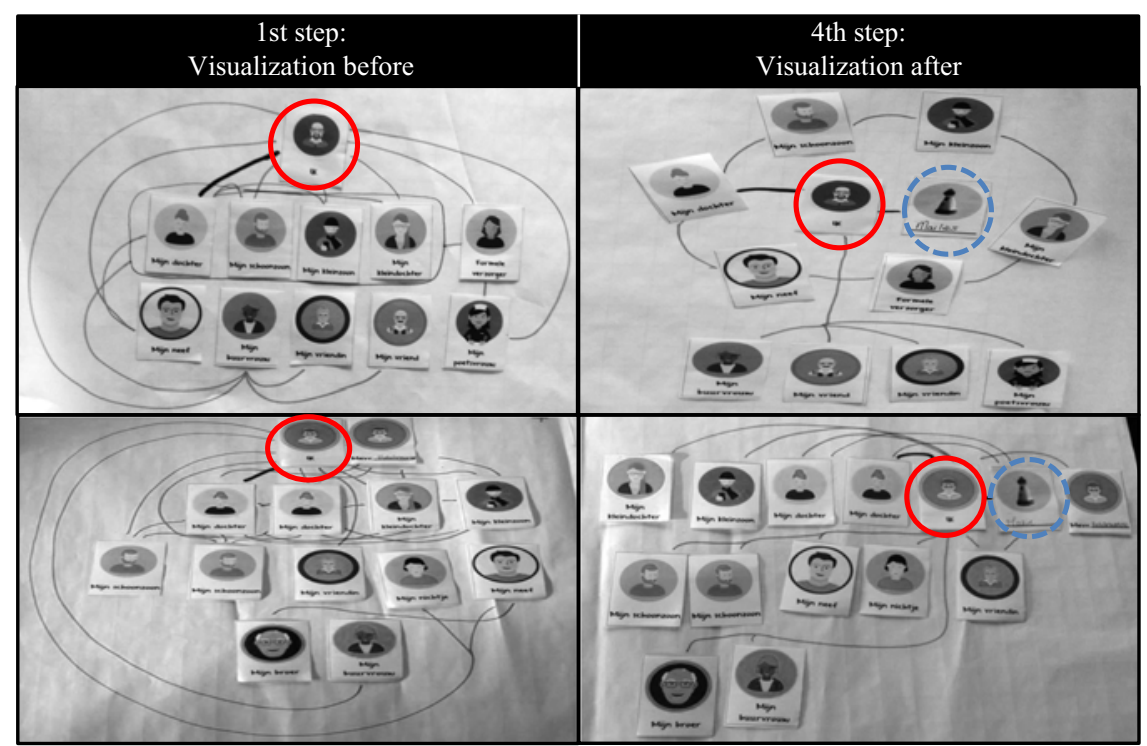

Notes: Elderly informants denoted by a red circle/solid line; robot by a blue circle/dashed line. Additional visualizations available via the corresponding author

homes or nursing homes, and lasted 40-90 minutes with an average length of 70 minutes. Four data collection waves over the course of ten months continued until theoretical saturation was reached. All collected interviews were digitally audio-recorded, and any visualizations created were photographed.

\section{Data analysis}

To gain a comprehensive understanding of the anticipated value co-creating/destroying roles that socially assistive robots play in elderly persons' care-based value networks, the authors undertook an iterative process with simultaneous data collection and analysis. After each data collection wave, the interviews were transcribed, translated, and reviewed, resulting in 326 single-spaced pages of text. Themes emerging from the analysis were further examined in subsequent interviews, in an attempt to reach closure (Lincoln and Guba, 1985). First, the authors read the transcripts independently to form their own understanding of each informant's narratives (Riessman, 1993) and applied segment-to-segment coding to depict robots' roles in the network. Second, the authors met for a joint analysis session to share emerging, initial codes and develop a more focused coding scheme for the subsequent analysis (Charmaz, 2014). Third, the first two steps were repeated for each data collection wave, ultimately producing jointly defined robot role categories.

The units of analysis were the individual abstractions of current and future care-based value networks, with a particular focus on the role of the socially assistive robot among the constellation of actors. In this phenomenographic approach (Schembri and Sandberg, 2002), codes and the thematic descriptions emerged from the data, rather than relying on the existing classifications (e.g. Robinson et al., 2014; Roy et al., 2000). This approach is not completely free of previous knowledge or experiences; rather, it allows for the emergence of new theory from the angle of value co-creation and co-destruction. As the data analysis evolved, additional literature provided meaningful comparisons with the identified roles of the socially assistive robot to achieve the desired value outcomes. 


\section{Results}

Guided by the codes emerging from the verbal data and supported by collected visual artifacts, the authors derived a typology (Doty and Glick, 1994) that reflects the focal actors' conceptualizations of the robots' expected roles in the value networks. As indicated in Table II, the top row reveals three desired value outcomes that elderly people strive for and hope to realize within their value networks: 1 . physical health, 2 . psychosocial health, and 3. cognitive health. To achieve these desired value outcomes, the elderly informants cluster the services that the socially assistive robot can offer into three, respective supporting functions: 1.1 safeguarding, 2.1 social contact, and 3.1 cognitive support. Furthermore, from these elderly informants' perspectives, each supporting function provided by the socially assistive robot has two counterparts or anticipated roles: one with high value co-creation potential and one with high value co-destruction potential.

The Context Disruption interviews and Contextual Value Network Mapping technique also aimed to collect in-depth insights on disruptive effects of a service innovation. The uniqueness of these methods stems from their focus on the value-creating practices of focal network actors (elderly) and concomitant acknowledgment of the effects on other, interdependent network actors (formal and informal caregivers). This network-conscious approach induces network thinking among informants, because the use of the tangible artifacts makes the elderly informants aware of the other actors in the network. Through the generative activity, by which they mapped their network context, informants shared narratives, including idiosyncratic views of how socially assistive robots affect other network actors (e.g. family members, nurses), positively or negatively. The findings pertaining to the other network actors support an emergent typology of roles, as empirically illustrated in Table II and described subsequently. They reflect elderly people's perspectives on how robots' supporting functions (safeguarding, social contact, and cognitive support) can be beneficial (value co-creating potential) or detrimental (value co-destroying potential) for formal and informal caregivers in their network.

\section{Physical health}

Falls among the elderly are an alarming problem, often causing hospitalization and reduced physical autonomy due to severe injuries (World Health Organization, Ageing and Life Course Unit, 2008). Accordingly, the first desired value outcome that elderly people identified in this study is to maintain good physical health and delay physical decline. From the narratives shared by the elderly informants, it is evident that older people face some inevitable physical difficulties, particularly associated with mobility, such that many informants shared stories of falling and the serious injuries that resulted. For example, one informant explained:

Recently, I fell in my room and I couldn't move. I had wounds all over my elbows and legs from how much I fought [to get help]. I barely managed to reach my bed. And I don't know how much time it took me to get to my senses [...]. And the feeling is awful! You are on the floor and cannot help yourself (Mr. Davis).

In situations such as this, elderly people depend on a prompt reaction from their formal or informal caregivers, who can ensure adequate medical attention and care. In addition, an imperative of elderly care is to find ways to circumvent falls, by encouraging physical activity or preventing potential safety risks. Unfortunately though, even with proper attention, caregiving services often are not available $24 / 7$, so accidents take place.

\subsection{Safeguarding}

As a response to the raised issues, one of the emergent supporting functions of socially assistive robots is safeguarding elderly people. It combines systematic and continuous monitoring, such that the robot can call for help immediately in the case of an emergency, 


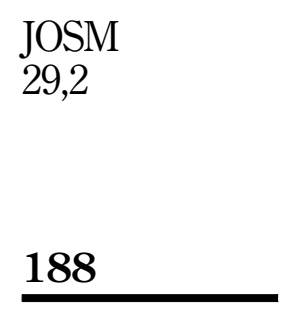

Table II.

Typology of roles
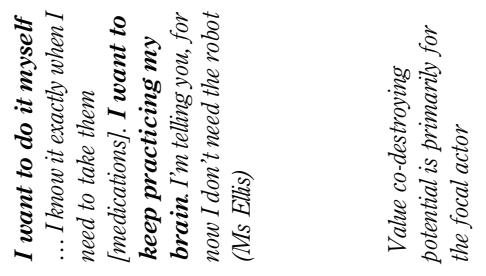

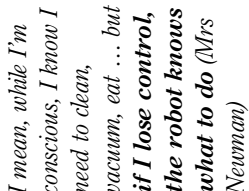

ฐ⿱艹

₹

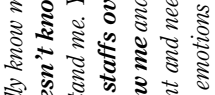

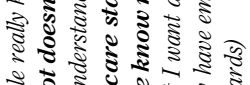

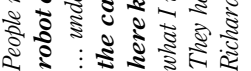

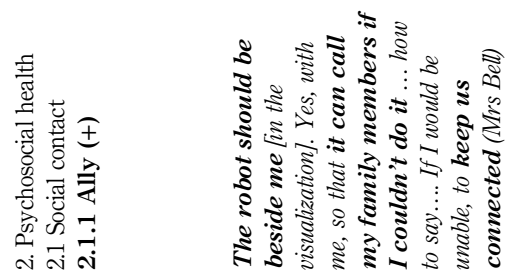

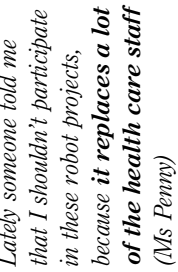

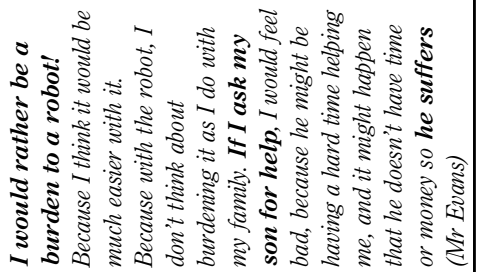

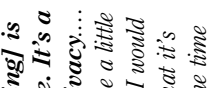

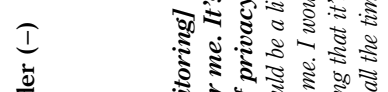

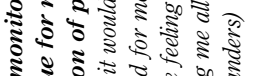

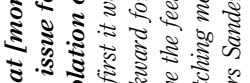

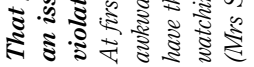

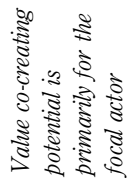

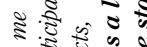
उ. 弯 की

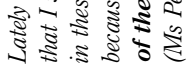

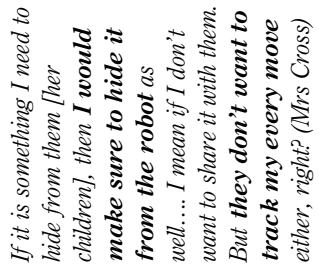

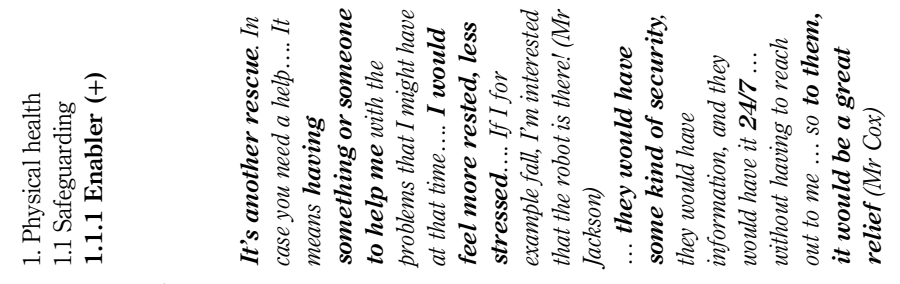

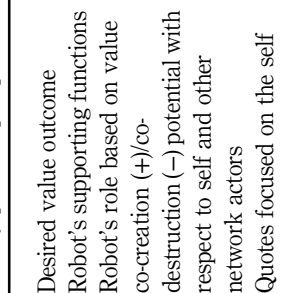


and offer spatial guidance by warning people of potential obstacles and raising alarms when they are susceptible to environmental threats. This function is primarily dedicated to protecting elderly people's physical health, which is a repeatedly emphasized and desired value outcome of interactions with socially assistive robots:

I could live a more quality life because I could rely on [the robot] that in case I need help, it will notify whoever is needed. That is a feeling of security that we lose with the old age. And physical safety brings us back the relaxation and then we can enjoy more in the few years of life we are left with (Mrs Moore).

Although the socially assistive robot's safeguarding function thus can be conducive to attaining the desired value outcome of physical health, it also might destroy existing value (e.g. privacy) from the perspective of the focal actors, which could explain their reluctance to accept robotic innovations. Through a value co-creation/destruction lens, the robot embodies roles of being either an enabler or an intruder.

\subsubsection{Enabler role}

As an enabler, the robot is perceived to have a considerable value co-creation potential, because it empowers the focal actor and other network actors. Visions of the robot as an enabler in the care-based value network primarily result from its task of detecting falls or other accidents, then alerting predefined (in)formal caregivers. Thus, the robot is a lifeline to a quick medical assistance. Many informants note the importance of systematic monitoring to ensure prompt reactions by medical staff:

That's the most important to me. That I can receive instant help. If needed, to directly transfer me to the hospital (Mr Richards).

The robot co-creates value through health monitoring, its constant presence, security guarantee, and alert system; the elderly persons co-create it through their trust, cooperation, and acceptance. The informants in turn identify benefits including feelings of safety and secure rescue options:

I am afraid I will fall again in the future! [Having a robot] would give me a relief. It just gives a comfortable feeling [...]. Quick reaction is essential in case of an emergency (Ms Gray).

The network-conscious approach also reveals elderly people's opinions about how the safeguarding function might contribute to value co-creation with other network actors. The informants frequently assigned benefits to their informal caregivers, who would gain the positive outcomes of time savings, peace of mind, and alleviated stress. As described by one of the informants:

They [her family members] are in contact with it and they know what's happening to me. They can go to work and do not have to worry. Because while they are at work, they don't have to think whether something has happened to me, because they know they would be notified. That is some kind of security for them (Mrs Bell).

\subsubsection{Intruder role}

However, not all informants share these views, such that they may be reluctant to welcome the automated actor into their homes. As an intruder, the robot is perceived to have considerable value co-destruction potential, because it interferes with the space possessed by the focal actor and other network actors. In this case, elderly people express unwillingness to cooperate with the robot, and they denote the robot's invasiveness primarily through the prism of continuous monitoring. Expressions like "It's like having a Big Brother in my apartment" (Mrs Cross) or "It will be watching me all the time and I don't like that" (Mr King) signal feelings of an intrusion of privacy evoked by the robot. 
JOSM

29,2

190

The trade-offs associated with the intruder role are dominated by its value co-destroying potential, as shown by the following quote:

The robot could be useful because it could help [...] but to rely on the robot only [...]. I wouldn't want that [...]. I wouldn't feel comfortable with it. No one likes to be monitored at all times [...]. I don't rely on technology, I rely on people [...]. The robot can be helpful but it cannot really help! (Mrs Moore).

These feelings of privacy violation are accompanied by decreased trust and increased uneasiness, discomfort, and irritation, which ultimately produce strong aversive feelings toward the robot. Safeguarding thus could become a hindrance to the realization of physical health value outcomes, as the following quote indicates:

I see that robot and I wonder what is it here for? What's its use? It would just be standing in a corner I think (Mr Cooper).

In the network-conscious approach evoked by this study, the elderly informants also describe the robot's potential to co-destroy value relative to other network actors, such as their family members, formal caregivers, or peers. For example, one informant, noting his informal connections, anticipated:

I think my granddaughter will find it a bit scary [...]. And I also hear from a lot of people here [other residents] that they don't want it in their room, because it sees everything. Me myself, I wouldn't mind (Mr Butler).

\section{Psychosocial health}

Ageing is linked to not just physical decline but also social deprivation in many cases (Banks et al., 2008). People who reach old age lose some of their social contacts (due to the death of peers) and are more prone to experience loneliness and other psychosocial problems. The changing lifestyles of working populations also imply that informal caregivers often have less time to care for their elders (e.g. visit daily, live with them), which further induces feelings of solitude among the focal actors. Thus, the second desired value outcome is preserving and/ or enhancing psychosocial health, as one of the informants explained:

[...] and children have their own obligation. They can help only financially if something like that [elderly living independently] would happen. And no one can really stay with you. Because those times have passed when people could stay with sick and old parents. It's not happening today. Everyone's children have left [...] they are working and cannot abandon their jobs to serve you. It's the life; we are living in a different era. Things have changed significantly (Mrs Newman).

\subsection{Social contact}

In response to this problem, the second emergent function of socially assistive robots is to provide social contact. Existing research shows that the acceptance of socially assistive robots is increasing among seniors, especially if they are seen less as metal machines and more as human-like companions (Dautenhahn, 2007; Robinson et al., 2014). Socially interactive and socially assistive robots can communicate with humans, read and express emotions, suggest activities based on the person's mood, and scale up their social competencies (Dautenhahn, 2007). Consider the following perceived benefits of such functionalities:

At my age it's not easy to find new friends. And it's not like I'm looking for ones. But it all leads to being lonely. With the robot I wouldn't feel that way anymore. I would always have someone to talk to, share my thoughts, not to talk to myself anymore [laughs]. This aspect of the robot is what I like the most. It would be a company and entertainment. Life would be nicer (Mr Davis). 
As evaluated by the focal actors, this social contact function of the robot can have value co-creating and value co-destroying potential. The empirical evidence reveals two robot roles in this function: ally and replacement.

\subsubsection{Ally role}

As an ally, the robot is perceived to have a considerable value co-creation potential, by collaborating with various network actors. Within care-based value networks, allies can engage in two activities. First, the robot can increase social engagement by directly interacting with elderly people or by facilitating social contacts with other network actors. Because of its social capabilities, the robot can accommodate the psychosocial needs of elderly people, as indicated in the following quote:

It [the robot] would be a friend. I would name it Boni, because it was a dog I loved a lot [...]. Yes, because Boni was very loyal to me (Ms Ellis).

Second, the robot can act as a communication and information-sharing interface that facilitates connections to the existing social contacts of the focal actor:

Because who has no one, who only has people on the outside [of the nursing home], this communication services are very important [...]. It [the robot] could intensify the relationship with my friends. Yes, because I could talk more often with them (Mrs Smart).

When prompted to think about the positive effects of introducing socially assistive robots on other actors in their value networks, the elderly informants frequently indicated how the supporting function of social contact might unburden their caregivers, as indicated in this network-conscious response:

Yes, the robot would call them [her household members] and transfer to them, I think, the information about what's going on with me. It would be of a help. It would be our friend. To me it would be much more acceptable to depend on the robot, to for example, unburden my household members (Ms Ellis).

\subsubsection{Replacement role}

Some of the informants instead expressed anxiety and fear that the robot might negatively affect their social networks and lead to even more social isolation. The role of a replacement implies that the robot is perceived to have considerable value co-destruction potential, by substituting for various network actors. The elderly informants frequently noted their concern that the robot might replace their human caregivers, deprive them of social interactions, and ultimately cause deterioration in their psychosocial health:

For the short time I have left, give me real people who are alive. It [the robot] doesn't live. The whole robot is just a dead person (Mr King).

Furthermore, the elderly informants fear that their network contacts might start neglecting them, because they could rely on the robot's alert system. As one informant explained:

I'm afraid it will take a lot of my contacts from me [...]. I would like to stay in charge [...] I'm afraid to lose this contact in case the robot would take over things [...]. And then I'll become a number $[\ldots]$. I'm afraid that things get less personal [...] it's already getting worse $[\ldots]$. We should make sure that the robot doesn't take over too much. The robot is and will be made of metal (Ms Penny).

When thinking about other network actors, the elderly primarily emphasized their fear that if the robots were to succeed in replacing humans, caregivers inevitably would suffer job losses. 
JOSM

29,2

In addition, humans might become dispensable and potentially pushed out of care-based networks, as the following quotes indicate:

First I'd like to say that I do not want this development [robotic technology] to be at the cost of the employees (Mrs Summers).

The only thing that really frightens me is if it would replace the caregivers (Mrs Sanders).

\section{Cognitive health}

Finally, various levels of cognitive decline and dementia affect the ageing segment of the population and accelerate their early institutionalization (Black et al., 1999). Among the interviewed sample, elderly informants repeatedly reported varying degrees of forgetfulness or decreased memory:

Sometimes I don't know where I left something. For example my phone. So I start calling it, and hear the ringtone somewhere, but I'm not able to locate in the room by myself (Mr Richards).

I can't find anything [laughs]. I lose my keys, I lose this, I lose that (Mr King).

As a result of the decline in their cognitive abilities, the elderly become more reliant on their caregivers, which affects their self-esteem and feelings of self-efficacy. Many informants vocalized their desire to stay independent for as long as possible:

My mother is 95 years old and is able to take care of her medicine totally by herself [...] and she takes more than 15 capsules per day. She is my role model. I would like to grow old like her. With dignity and independence (Ms Gray).

\subsection{Cognitive support}

The last identified supporting function of the socially assistive robots thus is cognitive support. Increased forgetfulness in daily routines can lead to many unwanted consequences (e.g. neglected health due to poor medicine intake, eroded dignity due to an inability to track physiological needs). Socially assistive robots can minimize the negative effects of cognitive impairments by offering systematic cognitive reminders (Pineau et al., 2003). As described by one of the informants:

If I would need it [the robot], I would need it for the alarm, the medication service and for the reminders. My memory is still good, but who knows what will be in five years' time. My wife lost her memory in six weeks' time. Then a robot would be useful (Mr Butler).

However, some informants see the cognitive support as having value co-destroying potential. The empirical evidence thus identifies two additional robot roles, specifically, extended self and deactivator.

\subsubsection{Extended self role}

The role of an extended self implies that the robot is perceived to have considerable value co-creation potential through its ability to augment the focal actor's capabilities. The robot often was described as part of the elderly person's extended self (Belk, 2013), because it enables them to prolong their independence and normal living routines. The perceived benefits can be seen in the following quote:

That's useful [agenda reminders]! It will help me remember appointments [...]. And it would be great if it [the robot] would tell to me to stay off the candy! [...] And it would come in handy to remind me to buy groceries I buy less often (Mrs Summers). 
Many elderly informants acknowledge that cognitive support would be an ideal function for others, such as peers or other residents in the nursing home, but did not consider themselves in need of such services. For example:

People my age usually take many pills, so for them it would be useful for sure. A person loses himself. At one time she drinks blue pills, then green, then pink, then white. Who could remember? But thank goodness I have no such problems (Mrs Moore).

\subsubsection{Deactivator role}

Despite the described value creation potential of the cognitive support function, some informants fear that it only accelerates mental decline. In the role of a deactivator, the robot is perceived to have considerable value co-destruction potential, by disengaging the focal actor. This strong value co-destruction potential results from two perceived threats, such that reduced mental activation might lead to cognitive deterioration, and relying on the robot feels like "giving up" or losing control over one's own life. The following quotes illustrate these deactivator roles of the robot:

I can still think for myself [...]. I think it's important to keep thinking for yourself, otherwise you get lazy (Mr Wheeler).

If I'm able to do it by myself, I should do it instead of the robot. At a certain point in time you fall asleep/drop off if you let the robot take the responsibility. So no, I want to keep control in my hands (Ms Penny).

Distinctly, the extended self and deactivator roles are perceived to have more considerable value co-creation/destruction potential for the individual, focal actor, rather than on the network level. Even though these roles seemingly could have positive or negative consequences for other network actors (e.g. unburdening of informal and formal caregivers), when discussing the effects of the cognitive support function, the elderly informants primarily shared expected outcomes with respect to themselves.

\section{Discussion and implications}

This research investigates the potential roles of socially assistive robots in elderly care by taking the perspective of the focal network actor (i.e. elderly person). In-depth phenomenographic interviews, supported by generative card activities, collect vivid representations of how service beneficiaries co-create value within their value networks and how they expect these practices to change after the introduction of socially assistive robots. In this way, it empirically addresses a gap in service literature, by adopting a value transformation lens on future service (Witell et al., 2016). Furthermore, this study offers a more holistic perspective by investigating how the introduction of an automated agent (i.e. socially assistive robot) disrupts value-in-context, with respect to not only the self but also other, interdependent network actors. These results expand the knowledge base about socially enhanced technology (Danaher and Gallan, 2016; van Doorn et al., 2016), by uncovering how such novel value propositions disrupt institutionalized value creation, through both their value co-creating and their value co-destroying potential. The resulting finer-grained understanding of how to increase people's willingness to accept and reduce their resistance to socially assistive robots also produces some guidelines for offering meaningful value propositions for symbiotic human-robot interactions. Furthermore, it offers nascent strategic guidelines to achieve what Wirtz and Zeithaml (2018) call "cost-effective service excellence" through robotic innovations that have the potential to enhance the experience for a diverse set of network actors, while simultaneously improving service quality and productivity. 
JOSM

29,2

194

The results specify three prominent areas of support: physical, psychosocial, and cognitive health, in line with the existing research in social robotics (e.g. Glende et al., 2015). It also extends these findings by relating robots' supporting functions to the desired value outcomes, through their value co-creating and co-destroying potential. The proposed typology of socially assistive robots extends the existing research by defining robots' roles according to the value they can co-create with a service beneficiary, as well as the existing value that potentially could be co-destroyed. Furthermore, as Figure 5 indicates, the network-conscious approach yields a clearer understanding of which roles contribute more on an individual vs a network level. In particular, when analyzed according to the interplay of cognitive-physical-psychosocial desired value outcomes, robots' cognitive support roles, whether value co-creating (extended self) or value co-destroying (deactivator), mainly have the potential to enhance or inhibit value at the individual level (for the focal actor). The enabler and intruder roles stemming from the safeguarding function instead have co-creating/destroying potential for both the focal actor and the network (other network actors). Finally, the social support roles (ally and replacement) mainly have co-creation/destruction potential at the network level. In line with these results, the network-level roles might have the most resonating consequences for the entire caring network. Hence, in evaluating and welcoming technologies which offer such roles, service beneficiaries might move from trying to maximize the utility for themselves towards maximizing the utility for the entire network.

This understanding of individual- vs network-level value potential, from the perspective of a focal actor, offers important insights into the hindrances that must be mitigated or designed around to improve the receptivity of robots in an overall care-based value network. Not all value co-destruction potential can be eliminated through the design process though, so it continues to pose a barrier to the acceptance of robotic technology. As this study shows, robots' value co-destroying roles (e.g. intruder) should be counterbalanced by an emphasis on the value co-creating potential for other network actors (e.g. unburdening family members as an enabler) during the introduction phase.

Figure 5 .

Value co-creating and co-destroying roles

\begin{tabular}{|c|c|c|}
\hline \multicolumn{3}{|r|}{ t) takes a role of a/an... } \\
\hline & $\begin{array}{l}\text {... Replacement } \\
\text { If perceived to have considerable } \\
\text { value co-destruction potential by } \\
\text { substituting for various network } \\
\text { actors }\end{array}$ & $\begin{array}{l}\text {...Ally } \\
\text { If perceived to have considerable } \\
\text { value co-creation potential by } \\
\text { collaborating with various network } \\
\text { actors }\end{array}$ \\
\hline & $\begin{array}{l}\text {...Intruder } \\
\text { If perceived to have considerable } \\
\text { value co-destruction potential by } \\
\text { interfering with the space of the focal } \\
\text { actor and other network actors }\end{array}$ & $\begin{array}{l}\ldots \text { Enabler } \\
\text { If perceived to have considerable } \\
\text { value co-creation potential by } \\
\text { empowering the focal actor and } \\
\text { other network actors }\end{array}$ \\
\hline & $\begin{array}{l}\text {... Deactivator } \\
\text { If perceived to have considerable } \\
\text { value co-destruction potential by } \\
\text { disengaging the focal actor }\end{array}$ & $\begin{array}{l}\ldots \text { Extended self } \\
\text { If perceived to have considerable } \\
\text { value co-creation potential by } \\
\text { augmenting the focal actor }\end{array}$ \\
\hline Individual & $\begin{array}{c}\text { Value co-destruction } \\
\text { potential }(-)\end{array}$ & $\begin{array}{l}\text { Value co-creation } \\
\text { potential }(+)\end{array}$ \\
\hline
\end{tabular}


Communicating robot roles shapes expectations among the network actors and can have an important effect on the introduction of robots. In the process of becoming members of human society, robots need to assure humans that they are well-intended and trustworthy, and that they will give their best to minimize the risks of value co-destruction (Kuipers, 2016). In a healthcare environment, the question of whether the robots will take assistive and complementary roles or whether they will make human caregivers redundant and completely replace them remains unanswered. However, responsible service system designers need to take these questions into consideration (Metzler et al., 2016). In line with Huang and Rust (2018), mechanical tasks such as vacuuming (see Nielsen et al., 2016), medication reminders and monitoring for falls are more easily replaceable with robots than the high-touch tasks involving personal concern, companionship, and genuine emotional responses.

This study thus contributes to the service literature in three main ways. First, it indicates that automated actors, such as socially assistive robots that offer assistive value propositions through social means, can be evaluated similarly to human actors. Specifically, robots equipped with both assistive and social resources appear comparable to human actors in phenomenologically defined value networks. The collected narratives reveal that the elderly informants perceive robots as capable of engaging socially (i.e. high on automated social presence; van Doorn et al., 2016), with both value co-creating and co-destroying potential, as well as considerable impact at individual and network levels. Thus, technology equipped with facial and voice recognition abilities can invoke perceptions of different anthropomorphized functions and roles. The human-like traits distinguish socially assistive robots from, for example, self-service technologies (Meuter et al., 2005), which do not have an active value co-creating/destroying role for the realization of desired value outcomes, from the focal actor's perspective. By acknowledging the potential to co-destroy value, this study also extends existing conceptualizations of healthcare robots. For example, Roy et al. (2000) identify five primary functions (cognitive prosthesis, safeguarding, systematic data collection, remote tele-medicine, and social interaction) but highlight only the positive consequences of these functions. Acknowledging how such functions may harm a service beneficiary is especially important in healthcare settings, which involve vulnerable service recipients and high-delivery risks (Berry and Bendapudi, 2007). This ambidextrous perspective offers a more balanced view on socially assistive robots and thereby advances research on the complementary and substitutive nature of technology in service networks.

Second, this study extends the scholarly understanding of value creation practices, through its network-conscious approach that uncovers both positive and negative expectations of future service scenarios. The resulting typology identifies several potential roles of automated actors and also integrates evaluations of the impacts of technology on not only the informants themselves but also the other actors in their value networks. This proposed typology thus extends the existing role conceptualizations (e.g. Frow et al., 2016; McColl-Kennedy et al., 2012; Moeller et al., 2013), to encompass value cocreation and co-destruction counterparts, but also to address network-conscious elements. Moreover, this study clarifies future service scenarios, according to the anticipated value co-creation/destruction roles and potential changes in value-creating/destroying practices, even before the technology is introduced. This novel focus on future rather than current value co-creation and co-destruction can stimulate service innovations in complex service systems such as healthcare (Danaher and Gallan, 2016). Evaluating technologies before deploying them also offers opportunities to mitigate future value co-destruction, by designing around hindrances to value realization. These results suggest important guidance for service managers who are formulating new value propositions (Skålén et al., 2015). In the design process, they must foster value co-creation potential, while also minimizing value co-destruction potential, to encourage the more seamless introduction of the service innovation. 
JOSM

29,2

196

Third, the network-conscious approach to technology-enabled services advances prior literature on complex service systems (Chandler and Lusch, 2015) and value constellations (Normann and Ramirez, 1993). Because value co-creation/destruction knowledge depends deeply on high quality, phenomenological insights, this research field requires more finegrained, qualitative methods to illuminate idiosyncratic understanding of value-creating networks. As one option, this study introduces the Context Disruption interview method, which leverages Contextual Value Network Mapping to render vivid representations of current and future value constellations. The tangibility and collected visualizations also facilitate data-rich narratives, shedding light on both value co-creating and co-destroying practices of future service scenarios. In particular, when they evaluate innovations, service beneficiaries consider how the value co-creation/destruction trade-offs affect not just them but also other network actors. Value co-creation potential that benefits a close family member can offset value codestruction that harms the focal actor. For example, privacy violations may be outweighed by benefits associated with unburdening family members. This holistic perspective on service innovation reveals the network dynamics and disruptive effects of service innovation in relation to both the self and the other actors who will appear in future service constellations. With this methodological contribution, which encouraged the informants to engage in network thinking and explicate the network value co-creation/destruction potential of service innovation through both narratives and accompanying network visualizations, the authors also give service researchers a new way to address the key service research priority of designing adaptive service systems that can respond to dynamic environments (Ostrom et al., 2015).

\section{Managerial implications}

The proposed typology provides some early strategic guidelines for overcoming the challenges of robotic introductions, for at least three groups of relevant stakeholders. First, technology developers and service designers, interested in the widespread acceptance of their socially assistive robots, need to focus on the service beneficiary approach and harness the power of the in-depth contextual understanding provided herein. Their better comprehension of actors' desired value outcomes and perceptions of health-related enhancers and inhibitors should result in robotic solutions that are better tailored for successful value co-creation. They should account particularly for the identified values (i.e. physical, psychosocial, and cognitive health) and ensure the functions of the robots improve their value co-creating potential. With a better understanding of how different functionalities contribute to current value creation practices, but also how they potentially impede the continuation of existing value within service networks, technology developers and service designers have a better chance to realize a quantum leap in service improvements for the benefit of service beneficiaries

Second, when introducing complex robotic solutions, service managers (e.g. assisted living facility managers) would benefit from taking a value network perspective rather than focusing on only one group of stakeholders. They should be guided by the interplay among the physicalpsychosocial-cognitive health desired value outcomes. Before they design introductions or communication materials, they might screen elderly residents to determine their attitudes, then cluster them in different target groups, depending on their primary desired value outcomes. Furthermore, training programs for the involved personnel should sensitize them to the most frequent value co-creation/destruction themes. Finally, two-sided communications (e.g. user tutorials, training, flyers) should acknowledge elderly people's fears (value co-destruction potential) while accentuating the positive value outcomes for a diverse set of actors, in an effort to increase receptivity to and encourage adoption of socially assistive robots.

Third, involved healthcare personnel should realize that elderly people often perceive robotic technology as a threat or a challenge, so they need to strive to facilitate more positive feelings and increase perceptions of the usefulness of the innovation. In so doing, they can 
make the elderly more eager to allow the socially assistive robot into their care-based network contexts. Activities that might foster robotic technology acceptance include acknowledging concerns and suggesting means to circumvent possible value co-destruction, harnessing network influences by emphasizing the value co-creation potential for formal and informal networks, helping people understand how their desired value outcomes can be achieved by accepting socially assistive robots, and providing strong privacy protections.

\section{Limitations and further research}

Although this study offers an interesting perspective on current and future human-robot value co-creation/destruction in a healthcare context, it also contains some research limitations. First, the interview data are rich and support in-depth explorations of the involved actors, yet the time-consuming nature and challenging informant recruitment of this approach limits the breadth of the researched sample. The collected phenomenographic insights are thus limited to an elderly care context in Europe. Continued research might consider other healthcare or non-healthcare service settings and other geographic areas. Second, the collected data are cross-sectional, which restricts further analyses of the actors' actual behavioral changes, though they might offer a more comprehensive understanding of their adoption of new technology. The theoretical framework and typology, grounded in qualitative data, thus open avenues for quantitative and/or longitudinal research.

Third, the research scope was limited to focal network actors, thereby neglecting the perspectives of other network actors. Further research could include the perceptions of the formal and informal caregivers, which could provide a fuller network perspective on value co-creation/destruction. Such an effort would address the service research priority suggested by Ostrom et al. (2015) and Barile et al. (2016), namely, to enhance understanding of multi-actor, network, and collaborative value creation in complex service systems. Fourth, the informants did not experience socially assistive robots becoming part of their care-based value networks; rather, they tried to envision how such a disruption would transform their interactions within the network. Therefore, the proposed Context Disruption interview approach should be used with caveats, especially in situations in which informants face difficulties foreseeing how service innovations might affect their lives or network configurations. For this particular study, the recruited elderly informants were part of the pretrial phase of a socially assistive robot project, so they had been introduced to the robot previously. Furthermore, the robot supported functions that the informants were already familiar with (e.g. fall detection, Skype communication, reminders), so it was possible for them to anticipate how it would change value co-creating interplays in their respective networks.

\section{Acknowledgments}

This project received funding from the European Union's Horizon 2020 research and innovation programme under the Marie Sklodowska-Curie Grant Agreement No. 642116. The information and views set out in this study are those of the author(s) and do not necessarily reflect the official opinion of the European Union. Neither the European Union institutions and bodies nor any person acting on their behalf may be held responsible for the use which may be made of the information contained therein. The authors acknowledge the elderly care units of Zorgcentrum Hoogstaete, Zuyderland Zorgcentra (the Netherlands), Cáritas Diocesana de Coimbra (Portugal), and the GrowMeUp project (www.growmeup.eu/) for their assistance in recruiting elderly informants. The authors particularly thank Roy Beumers, Carina Dantas, Charlotte Gijzen, Leonne Hollanders, Ana Luísa Jegundo, Noémi van Nie, Flávia Rodrigues, Romy Schurgers, Mark Steins, and Rachelle Wintjens for their support during the data collection. 
JOSM

29,2

\section{References}

Augusto, J.C., Huch, M., Kameas, A., Maitland, J., McCullagh, P., Roberts, J., Sixsmith, A. and Wichert, R. (2012), Handbook of Ambient Assisted Living: Technology for Healthcare, Rehabilitation and Well-Being, Vol. 11, IOS Press, Amsterdam.

Banks, M.R., Willoughby, L.M. and Banks, W.A. (2008), "Animal-assisted therapy and loneliness in nursing homes: use of robotic versus living dogs", Journal of the American Medical Directors Association, Vol. 9 No. 3, pp. 173-177.

Barile, S., Lusch, R., Reynoso, J., Saviano, M. and Spohrer, J. (2016), "Systems, networks, and ecosystems in service research", Journal of Service Management, Vol. 27 No. 4, pp. 652-674.

Belk, R.W. (2013), "Extended self in a digital world", Journal of Consumer Research, Vol. 40 No. 3, pp. $477-500$.

Berry, L.L. and Bendapudi, N. (2007), "Health care a fertile field for service research", Journal of Service Research, Vol. 10 No. 2, pp. 111-122.

Black, B.S., Rabins, P.V. and German, P.S. (1999), "Predictors of nursing home placement among elderly public housing residents", The Gerontologist, Vol. 39 No. 5, pp. 559-568.

Black, H.G. and Gallan, A.S. (2015), "Transformative service networks: cocreated value as well-being”, The Service Industries Journal, Vol. 35 Nos 15/16, pp. 826-845.

Breazeal, C. (2004), "Social interactions in HRI: the robot view", IEEE Transactions on Systems, Man, and Cybernetics, Part C (Applications and Reviews), Vol. 34 No. 2, pp. 181-186.

Breazeal, C., Dautenhahn, K. and Kanda, T. (2016), "Social robotics", in Siciliano, B. and Khatib, O. (Eds), Springer Handbook of Robotics, Springer International Publishing, Berlin, Heidelberg, pp. 1935-1972.

Breidbach, C.F. and Maglio, P.P. (2016), "Technology-enabled value co-creation: an empirical analysis of actors, resources, and practices”, Industrial Marketing Management, pp. 73-85.

Briscoe, G., Keränen, K. and Parry, G. (2012), "Understanding complex service systems through different lenses: an overview", European Management Journal, Vol. 30 No. 5, pp. 418-426.

Broadbent, E., Stafford, R. and MacDonald, B. (2009), "Acceptance of healthcare robots for the older population: review and future directions", International Journal of Social Robotics, Vol. 1 No. 4, pp. 319-330.

Broekens, J., Heerink, M. and Rosendal, H. (2009), “Assistive social robots in elderly care: a review”, Gerontechnology, Vol. 8 No. 2, pp. 94-103.

Chandler, J.D. and Lusch, R.F. (2015), "Service systems: a broadened framework and research agenda on value propositions, engagement, and service experience", Journal of Service Research, Vol. 18 No. 1, pp. 6-22.

Charmaz, K. (2014), Constructing Grounded Theory, 2nd ed., Sage Publications Ltd, London.

Chen, T.L., Ciocarlie, M., Cousins, S., Grice, P.M., Hawkins, K., Hsiao, K., Kemp, C.C., King, C.H., Lazewatsky, D.A., Leeper, A.E. and Nguyen, H. (2013), "Robots for humanity: using assistive robotics to empower people with disabilities", IEEE Robotics \& Automation Magazine, Vol. 20 No. 1, pp. 30-39.

Clatworthy, S. (2011), "Service innovation through touch-points: development of an innovation toolkit for the first stages of new service development", International Journal of Design, Vol. 5 No. 2, pp. 15-28.

Cova, B. and Salle, R. (2008), "Marketing solutions in accordance with the SD logic: co-creating value with customer network actors", Industrial Marketing Management, Vol. 37 No. 3, pp. 270-277.

Danaher, T.S. and Gallan, A.S. (2016), "Service research in health care positively impacting lives", Journal of Service Research, Vol. 19 No. 4, pp. 433-437.

Dautenhahn, K. (2007), "Socially intelligent robots: dimensions of human-robot interaction", Philosophical Transactions of the Royal Society B: Biological Sciences, Vol. 362 No. 1480, pp. 679-704.

Dautenhahn, K., Woods, S., Kaouri, C., Walters, M.L., Koay, K.L. and Werry, I. (2005), "What is a robot companion-friend, assistant or butler?", IROS Proceedings of the IEEE/RSJ International Conference on Intelligent Robots and Systems, IEEE, Edmonton, pp. 1192-1197. 
Doty, D.H. and Glick, W.H. (1994), "Typologies as a unique form of theory building: toward improved understanding and modeling", Academy of Management Review, Vol. 19 No. 2, pp. 230-251.

Echeverri, P. and Skålén, P. (2011), "Co-creation and co-destruction: a practice-theory based study of interactive value formation", Marketing Theory, Vol. 11 No. 3, pp. 351-373.

Epp, A.M. and Price, L.L. (2011), "Designing solutions around customer network identity goals", Journal of Marketing, Vol. 75 No. 2, pp. 36-54.

European Commission (DG ECFIN) and the Economic Policy Committee (AWG) (2015), "The 2015 ageing report: economic and budgetary projections for the 28 EU member states (2013-2060)", available at: http://europa.eu/epc/pdf/ageing_report_2015_en.pdf (accessed April 17, 2017).

Feil-Seifer, D. and Matarić, M.J. (2005), "Defining socially assistive robotics", IEEE Proceedings of the 9th International Conference on Rehabilitation Robotics, Chicago, IL, pp. 465-468.

Feil-Seifer, D., Skinner, K. and Matarić, M.J. (2007), "Benchmarks for evaluating socially assistive robotics", Interaction Studies, Vol. 8 No. 3, pp. 423-439.

Fong, T., Nourbakhsh, I. and Dautenhahn, K. (2003), "A survey of socially interactive robots", Robotics and Autonomous Systems, Vol. 42 No. 3, pp. 143-166.

Frow, P., McColl-Kennedy, J.R. and Payne, A. (2016), "Co-creation practices: their role in shaping a health care ecosystem”, Industrial Marketing Management, Vol. 56, pp. 24-39.

Glende, S., Conrad, I., Krezdorn, L., Klemcke, S. and Krätzel, C. (2015), "Increasing the acceptance of assistive robots for older people through marketing strategies based on stakeholder needs", International Journal of Social Robotics, Vol. 8 No. 3, pp. 355-369.

Green, T., Hartley, N. and Gillespie, N. (2016), “Service provider's experiences of service separation: the case of Telehealth", Journal of Service Research, Vol. 19 No. 4, pp. 477-494.

Grönroos, C. (2008), "Service logic revisited: who creates value? And who co-creates?", European Business Review, Vol. 20 No. 4, pp. 298-314.

Huang, M.H. and Rust, R.T. (2018), "Artificial intelligence in service”, Journal of Service Research, February 5, available at: https://doi.org/10.1177/1094670517752459

Huijnen, C.A., Lexis, M.A., Jansens, R. and de Witte, L.P. (2016), "Mapping robots to therapy and educational objectives for children with autism spectrum disorder", Journal of Autism and Developmental Disorders, Vol. 46 No. 6, pp. 2100-2114.

International Federation of Robotics (2015), "World Robotics Survey: service robots are conquering the world", available at: www.ifr.org/news/ifr-press-release/world-robotics-survey-service-robotsare-conquering-the-world-772/ (accessed April 29, 2017).

KPMG (2016), "Social robots: 2016s new breed of social robots is ready to enter your world", KPMG Advisory N.V, Arnhem.

Kuipers, B. (2016), "Toward morality and ethics for robots", Ethical and Moral Considerations in Non-Human Agents, AAAI Spring Symposium Series, Palo Alto, CA.

Lincoln, Y.S. and Guba, E.G. (1985), Naturalistic Inquiry, Sage Publications, Thousand Oaks, CA.

Lusch, R.F. and Nambisan, S. (2015), "Service innovation: a service-dominant logic perspective", MIS Quarterly, Vol. 39 No. 1, pp. 155-175.

McColl-Kennedy, J.R., Vargo, S.L., Dagger, T.S., Sweeney, J.C. and van Kasteren, Y. (2012), "Health care customer value cocreation practice styles", Journal of Service Research, Vol. 7 No. 4, pp. 370-389.

McColl-Kennedy, J.R., Snyder, H., Elg, M., Witell, L., Helkkula, A., Hogan, S. and Anderson, L. (2016), "The changing role of the health care customer: review, synthesis and research agenda", Journal of Service Management, Vol. 28 No. 1, pp. 2-33.

Maglio, P.P., Vargo, S.L., Caswell, N. and Spohrer, J. (2009), "The service system is the basic abstraction of service science", Information Systems E-Business Management, Vol. 7 No. 4, pp. 395-406.

Matarić, M.J. (2017), "Socially assistive robotics: human augmentation versus automation", Science Robotics, Vol. 2 No. 4, pp. 1-2.

Metzler, T.A., Lewis, L.M. and Pope, L.C. (2016), "Could robots become authentic companions in nursing care?”, Nursing Philosophy, Vol. 17 No. 1, pp. 36-48. 
JOSM

29,2

Meuter, M.L., Bitner, M.J., Ostrom, A.L. and Brown, S.W. (2005), "Choosing among alternative service delivery modes: an investigation of customer trial of self-service technologies", Journal of Marketing, Vol. 69 No. 2, pp. 61-83.

Moeller, S., Ciuchita, R., Mahr, D., Odekerken-Schröder, G. and Fassnacht, M. (2013), "Uncovering collaborative value creation patterns and establishing corresponding customer roles", Journal of Service Research, Vol. 16 No. 4, pp. 471-487.

Nielsen, J.A., Andersen, K.N. and Sigh, A. (2016), "Robots conquering local government services: a case study of eldercare in Denmark", Information Polity, Vol. 21 No. 2, pp. 139-151.

Normann, R. and Ramirez, R. (1993), "From value chain to value constellation", Harvard Business Review, Vol. 71 No. 4, pp. 65-77.

Ostrom, A.L., Parasuraman, A., Bowen, D.E., Patricio, L., Voss, C.A. and Lemon, K. (2015), "Service research priorities in a rapidly changing context", Journal of Service Research, Vol. 18 No. 2, pp. 127-159.

Patrício, L., Fisk, R.P., Cunha, J.F. and Constantine, L. (2011), "Multilevel service design: From customer value constellation to service experience blueprint", Journal of Service Research, Vol. 14 No. 2, pp. 180-200.

Perry, J.C., Rosen, J. and Burns, S. (2007), "Upper-limb powered exoskeleton design”, IEEE/ASME Transactions on Mechatronics, Vol. 12 No. 4, pp. 408-417.

Pineau, J., Montemerlo, M., Pollack, M., Roy, N. and Thrun, S. (2003), “Towards robotic assistants in nursing homes: challenges and results", Robotics and Autonomous Systems, Vol. 42 No. 3, pp. 271-281.

Pinho, N., Beirão, G., Patrício, L. and Fisk, P.R. (2014), "Understanding value co-creation in complex services with many actors”, Journal of Service Management, Vol. 25 No. 4, pp. 470-493.

Plé, L. and Chumpitaz Cáceres, R. (2010), "Not always co-creation: introducing interactional co-destruction of value in service-dominant logic", Journal of Services Marketing, Vol. 24 No. 6, pp. 430-437.

Polanyi, M. (1967), The Tacit Dimension, University of Chicago Press, Chicago, IL.

Prahalad, C.K. and Ramaswamy, V. (2004), "Co-creation experiences: the next practice in value creation”, Journal of Interactive Marketing, Vol. 18 No. 3, pp. 5-14.

Ray, C., Mondada, F. and Siegwart, R. (2008), "What do people expect from robots?”, IROS Proceedings of the IEEE/RSJ International Conference on Intelligent Robots and Systems, Nice, pp. 3816-3821.

Riessman, C.K. (1993), Narrative Analysis, Vol. 30, Sage, Newbury Park, CA.

Robinson, H., MacDonald, B. and Broadbent, E. (2014), "The role of healthcare robots for older people at home: a review", International Journal of Social Robotics, Vol. 6 No. 4, pp. 575-591.

Roco, M.C. and Bainbridge, W.S. (2003), "Overview converging technologies for improving human performance", Converging Technologies for Improving Human Performance, Springer, Dordrecht, pp. 1-27.

Roy, N., Baltus, G., Fox, D., Gemperle, F., Goetz, J., Hirsch, T., Margaritis, D., Montemerlo, M., Pineau, J., Schulte, J. and Thrun, S. (2000), "Towards personal service robots for the elderly", Workshop on Interactive Robots and Entertainment, Vol. 25, Pittsburgh, PA, July.

Rust, R.T. and Huang, M.H. (2014), "The service revolution and the transformation of marketing science”, Marketing Science, Vol. 33 No. 2, pp. 206-221.

Sandberg, J. (2000), "Understanding human competence at work: an interpretative approach", Academy of Management Journal, Vol. 43 No. 1, pp. 9-25.

Sanders, E.B.-N. (2000), "Generative tools for co-designing”, in Scrivener, S., Ball, L. and Woodcock, A. (Eds), Collaborative Design, Springer-Verlag, London, pp. 3-12.

Scassellati, B., Admoni, H. and Mataric, M. (2012), "Robots for use in autism research", Annual Review of Biomedical Engineering, Vol. 14, pp. 275-294.

Schau, H.J., Muñiz, A.M. Jr and Arnould, E.J. (2009), "How brand community practices create value", Journal of Marketing, Vol. 73 No. 5, pp. 30-51.

Schembri, S. and Sandberg, J. (2002), "Service quality and the consumer's experience: towards an interpretive approach", Marketing Theory, Vol. 2 No. 2, pp. 189-205. 
Skålén, P., Gummerus, J., von Koskull, C. and Magnusson, P.R. (2015), "Exploring value propositions and service innovation: a service-dominant logic study", Journal of the Academy of Marketing Science, Vol. 43 No. 2, pp. 137-158.

Sleeswijk Visser, F. (2009), Bringing the Everyday Life of People into Design, TU Delft, Delft University of Technology, Delft.

Smith, A. (2015), "Older adults and technology use", Pew Research Center, available at: www. pewinternet.org/2014/04/03/older-adults-and-technology-use/ (accessed March 17, 2017).

Snyder, H., Witell, L., Gustafsson, A., Fombelle, P. and Kristensson, P. (2016), "Identifying categories of service innovation: a review and synthesis of the literature", Journal of Business Research, Vol. 69 No. 7, pp. 2401-2408.

Tax, S.S., McCutcheon, D. and Wilkinson, I.F. (2013), "The service delivery network (SDN) a customer-centric perspective of the customer journey", Journal of Service Research, Vol. 16 No. 4, pp. 454-470.

van Camp, J. (2017), "Review: Jibo social robot", available at: www.wired.com/2017/11/review-jibosocial-robot/ (accessed November 17, 2017).

van Doorn, J., Mende, M., Noble, S.M., Hulland, J., Ostrom, A.L., Grewal, D. and Petersen, J.A. (2016), "Domo Arigato Mr. Roboto: emergence of automated social presence in organizational frontlines and customers' service experiences”, Journal of Service Research, Vol. 20 No. 1, pp. 43-58.

Vargo, S.L. and Lusch, R.F. (2016), "Institutions and axioms: an extension and update of servicedominant logic", Journal of the Academy of Marketing Science, Vol. 44 No. 1, pp. 5-23.

Wirtz, J. and Zeithaml, V. (2018), "Cost-effective service excellence", Journal of the Academy of Marketing Science, Vol. 46 No. 1, pp. 59-80.

Witell, L., Snyder, H., Gustafsson, A., Fombelle, P. and Kristensson, P. (2016), "Defining service innovation: a review and synthesis", Journal of Business Research, Vol. 69 No. 8, pp. 2863-2872.

World Health Organization, Ageing and Life Course Unit (2008), WHO global Report on Falls Prevention in Older Age, World Health Organization, Geneva.

\section{Appendix 1}

\begin{tabular}{rlcl}
\hline No. & Pseudonym $^{\mathrm{a}}$ & Age & Living arrangements \\
\hline 1 & Ms Gray & 72 & Assisted living at home \\
2 & Ms Elis & 86 & \\
3 & Mr Richards & 90 & Independent living \\
4 & Mrs Cross & 61 & \\
5 & Mr Cox & 62 & \\
6 & Mrs Bell & 70 & \\
7 & Mrs Newman & 73 & \\
8 & Mr Jackson & 76 & \\
9 & Mr Evans & 78 & \\
10 & Mr Butler & 81 & \\
11 & Mrs Moore & 82 & \\
12 & Mr Pearson & 91 & \\
13 & Mrs Sanders & 78 & \\
14 & Mrs Smart & 81 & \\
15 & Ms Penny & 82 & \\
16 & Mr Cooper & 83 & \\
17 & Mrs Summers & 83 & \\
18 & Mr Davis & 86 & \\
19 & Mr King & 90 & \\
20 & Mr Wheeler & 94 & \\
& ne & &
\end{tabular}

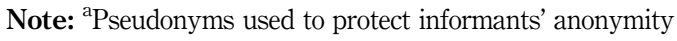

Table AI.

Overview of informants 
JOSM

29,2

\section{Appendix 2}

\section{Context Disruption interview - protocol}

The interviews were conducted in the elderly informants' homes or nursing facilities where they reside. Two hours were planned for each interview, which were conducted in private, usually in a meeting room (in nursing facilities) or dining room (in homes) that contained a large table or desk to perform the and ensure the quality of audio recordings. After signing the informed consent form and answering the initial set of demographic questions, informants began the four-step, generative, Context Disruption interview protocol.

Step 1: Contextual Value Network Mapping, status quo:

(1) Timing: approximately 30 minutes.

(2) Method: Generative technique/value-network mapping.

(3) TOOLS: Blank canvas, different color markers, and "actor network cards."

(4) Description: informants were asked to think about their everyday lives and different persons who take part in their "care-based value network" (defined as informal and formal connections who are more or less actively involved in taking care of them, from helping them with groceries, to medicine intake, to social aspects of their daily lives). They had to choose different network actors from the deck of cards and place them on the canvas on the table in front of them. They were asked to:

- organize and display their care-based value network;

- indicate the importance of each actor; and

- show connections between different actors using available colored markers. After this mapping activity, the interviewer used probing questions to collect narratives about each identified network actor and the existing relationships, such as:

- Why is this actor important to you (focusing on the care aspect)?

- What does s/he do for you?

- What does s/he mean for you?

- Do you feel like you are burdening this person?

- How would you feel if this actor were no longer part of your care network?

(5) Purpose: visualization of how elderly persons perceive their care-based value networks (for$\mathrm{mal}$ and informal). Collect information, from both what they say and what they make, to gain a better understanding of the key actors in networks, interactions among the actors, and actors' importance.

Step 2: Active immersion:

(1) Timing: approximately 15 minutes.

(2) Method: Critical incident technique/sensitizing to technology usage.

(3) Tools: $\mathrm{n} / \mathrm{a}$

(4) Description: informants were encouraged to share narratives of extremely satisfying or dissatisfying encounters they had with different types of technology (e.g. personal computers, smartphones, microwaves, Skype, dishwasher). The probing questions for satisfactory experiences included:

- Please try to remember a situation where you were extremely satisfied or fulfilled with usage of some new technology. Can you describe what led to your satisfaction?

- Why is this technology important for you? 
The probing questions for unsatisfactory experiences were:

- Please try to remember a situation where you were extremely dissatisfied and frustrated with usage of some new technology. Can you describe what led to your dissatisfaction?

- Do you ever feel helpless when being faced with some new technology?

- What would in your opinion have to change on this particular technology (design, additional services, etc.) so that you would be less frustrated by it, or so that you would not be dissatisfied with this technology?

(5) Purpose: to make informants sensitive to the key experience area (i.e. new technology) before introducing an unfamiliar technological impulse (i.e. socially assistive robot). Set the stage for Step 3, which introduces an automated actor that might evoke both pains and gains in informants' care-based value networks. Collect narratives on both frustrations elderly people face while using different types of technology but also on how technological advancements make their lives easier. By identifying different emerging themes (e.g. ease of use, instructions and explanations, design, time management), this step provided a finer-grained understanding of how value is created, as well as potential hindrances to value creation in various technology use situations.

Step 3: Introducing "disruption":

(1) Timing: approximately 35 minutes

(2) Method: laddering technique.

(3) Tools: canvas, robot photographs, "robot function cards."

(4) Description: informants were informed/reminded about the project, whose main goal was to develop an affordable, socially assistive robot for elderly people. Photographs of the robot in the company of the lead author, combined with detailed descriptions, were used to evoke its look and feel. Each of its 12 functions was introduced using a robot function card containing both a graphic and a label. The interviewer always followed the same order and the same description protocol, to avoid order effects, when introducing the functions:

- Medication service: this service will contain key medical information about the user, such as medication specifications, descriptions, and dosages. The robot will remind users to take medication in accordance with a pre-established schedule. It will also notify a caregiver when the elderly person refuses to take medication.

- Meal preparation assistance: this service will provide users with voice and video instructions during meal preparation. The robot will dictate recipes, suggest ingredients, remind users how to use kitchen appliances, and so on. Robots will not be able to cook, but they can give advice and describe the process, in case users forget certain steps during meal preparation.

- Communication via Skype: at the user's request, this service supports video or voice calls with family/friends/physicians and will provide help in creating contact lists. The user will not need to turn on a laptop or computer anymore but rather can connect through the robot's screen with the person they wish to talk to.

- Agenda service: this service will monitor users' daily routines and send reminders so that users do not forget their daily responsibilities (e.g. household chores, medical appointments, family visits). The robot will learn about users' routines through daily interactions.

- Organization of joint activities service: this service will inform users about events and activities in their neighborhood/community. Users will have an option to create an activity/event and invite other networked friends to join. 
JOSM

29,2

\section{4}

- Fall detector and alert service: this service will ensure continuous tracking of primary users (i.e. elderly people) and automatically inform their formal or informal caregivers if they fall or have any other type of accident.

- Motivation for physical activity: this service will stimulate and motivate users to engage in physical activity and support them during that physical activity, through voice and video instructions.

- Alarm clock: this service provides standard alarm clock settings but also enables users to choose the alarm music or ringtone they prefer.

- Nutritional advisor: this service will provide elderly persons with nutritional advice and remind them about balanced nutritive intake. For example, if the robot notices through its sensors that the temperature outside is higher than average, it will remind elderly persons to drink more water.

- Interactive games: this service will provide users with specially designed games to enhance their cognitive capabilities (depending on users' preferences).

- Object locator reminder: this service will provide reminders to elderly persons regarding where they usually leave objects in their homes. Some frequently used objects (e.g. keys, wallets, glasses) will have sensors so the robot knows exactly where they are.

- Shopping assistance service: this service will help users create grocery shopping lists and send the list to a person responsible for shopping (e.g. family members).

After all the functions were explained, informants were asked to indicate three functions that they deemed most important/useful, and then indicate three that they found least important/useful for their contexts. Next, the interviewer used a laddering technique to probe the top and bottom three functions, with the goal of eliciting core values:

- Why is this function important to you?

- (Depending on the reply) Why is important to you?

- (Depending on the reply) Why is important to you?

(5) Purpose: to acquaint informants with the robot so that they can assess and prioritize its functions, which in turn would help the researchers collect their genuine care needs and value priorities.

Step 4: Contextual Value Network Mapping, future condition:

(1) Timing: approximately 15 minutes

(2) Method: generative technique/value-network mapping

(3) Tools: blank canvas, different color markers, and "actor network cards"

(4) Description: informants were asked to imagine that the previously described robot had become a part of their care-based value network. They mapped how this intervention would change their current network contexts (which they previously mapped, in the first step). Starting from the blank canvas, they had to:

- again select the appropriate network actors;

- rearrange the selected cards into a conceptualized network configuration;

- place the new "robot card" within the network; and

- add the relationships among different actors.

After the Contextual Network Mapping activity, the interviewer asked:

- How would you name this robot? Would you consider it to be male or female? Please write the name on the line beneath the robot (on the card). 
- In your opinion, how will the introduction of the socially assistive robot change your everyday life?

- How will the lives/tasks of your formal and informal caregivers change?

- Who will be connected with the robot? Who will have access to the information from the robot?

- How would this intervention affect different interactions in the value network?

(5) Purpose: to determine whether and how the conceptualization and visualization of the care-based value networks changed relative to the first step (i.e. before vs after the introduction of the socially assistive robot). By collecting both what they say and what they do, this step again uncovered their thoughts, fears, dreams, and expectations with regard to this service innovation and their future network contexts.

\begin{abstract}
About the authors
Martina Čaic is a PhD Candidate at the Department of Marketing and Supply Chain Management at the Maastricht University and a Marie Curie Fellow at the Service Design for Innovation Network (SDIN). Her research focuses on customer experiences in value networks, with a particular interest in robotic and ambient assisted living technologies. Martina Čaić is the corresponding author and can be contacted at:m.caic@maastrichtuniversity.nl

Gaby Odekerken-Schröder is a Professor in Customer-centric Service Science at the Maastricht University, the Netherlands. Her main research interests are service innovation, relationship management, customer loyalty, and service failure and recovery. She is a Partner of the European consortium Service Design for Innovation, and her research has been published in Journal of Marketing, MISQ, Journal of Retailing, Journal of Service Research, Journal of Service Management, Journal of Business Research, and many more.

Dominik Mahr is an Associate Professor of Strategic Marketing \& Innovation Management at the Maastricht University. He is also a Scientific Director of the Service Science Factory. His research centers on recent marketing and innovation phenomena including open innovation, virtual social communities, online innovation brokers, customer co-creation, service design, and the development of new services. He has published in high-impact journals. Prior to his academic career, Dr Mahr worked for several years in different management and marketing consultancies, operating in industries such as high-tech, automotive, real estate, and insurance.
\end{abstract}

For instructions on how to order reprints of this article, please visit our website: 